\title{
Effects of Computer-based Stress Management Training on Psychological Well-being and Work Performance in Japanese Employees: A Cluster Randomized Controlled Trial
}

\author{
Rino UMANODAN ${ }^{1 *}$, Akihito SHIMAZU ${ }^{1}$, Masahide MINAMI ${ }^{2}$ and Norito KAWAKAMI ${ }^{1}$ \\ ${ }^{1}$ Department of Mental Health, Graduate School of Medicine, The University of Tokyo, Japan \\ ${ }^{2}$ Department of Public Health / Health Policy, The University of Tokyo, Japan
}

Received November10, 2013 and accepted June 20, 2014

Published online in J-STAGE July 24, 2014

\begin{abstract}
This study evaluated the effectiveness of a computer-based stress management training (SMT) program in improving employees' psychological well-being and work performance. A total of 12 work units $(N=263)$ were randomly assigned to either an intervention group (8 work units, $n=142$ ) or to a wait-list control group ( 4 work units, $n=121$ ). All participants were requested to answer online questionnaires assessing psychological well-being as a primary outcome, and coping style, social support, and knowledge about stress management as secondary outcomes at baseline (T0), immediately after the intervention (T1), and 2 months after the intervention (T2). The group $\times$ time interaction was tested using a mixed-model repeated measures ANOVA. Results showed a group $\times$ time interaction for "knowledge about stress management" in the entire sample. Among participants who had more than $3 \mathrm{~d}$ of training, a significant group $\times$ time interaction was observed for "problem-solving" and "avoidance and suppression" as well as "knowledge about stress management." Our computer-based stress management program was effective for improving knowledge about stress management. It was also effective for improving coping skills in instances where participants had enough time (at least 3 d) to complete all sessions.
\end{abstract}

Key words: Cluster randomized controlled trial, Computer based stress management training program

\section{Introduction}

Stress management training (SMT) is provided as a psychoeducational program to enable individual workers to learn how to become aware of and develop effective skills to cope with stress ${ }^{1)}$. Several SMT techniques are used in work settings, such as cognitive-behavioral training,

*To whom correspondence should be addressed. E-mail: rino-uma@umin.ac.jp

(C)2014 National Institute of Occupational Safety and Health personalized feedback based on systematic assessment, relaxation training, physical fitness training, and various combinations of these approaches ${ }^{2-4)}$. A recent metaanalysis of SMT has shown that cognitive-behavioral techniques are more effective than other techniques for enhancing psychological resources and reducing the psychological distress of employees ${ }^{3,5)}$.

Cognitive-behavioral techniques, such as cognitive restructuring skills, social skills, and problem-solving skills, are explicitly aimed at enhancing individual coping skills ${ }^{6}$. Coping refers to cognitive and behavioral efforts to manage specific demands that are appraised as taxing or 
exceeding the resources of the person ${ }^{7}$. Previous studies suggest that SMT programs with cognitive-behavioral techniques were effective for improving coping skills ${ }^{8-10)}$.

In addition to coping skills, interpersonal relationships (i.e., social support, or lack thereof, and interpersonal problems) have been found to be critical in determining employees' psychological distress. For instance, social support helps an employee exert situational control through the provision of instrumental aid or advice about how to modify a situation to make it less stressful ${ }^{7}$. Furthermore, the workplace community is one of the factors that contributes to reducing employee burnout rates ${ }^{11)}$. Lack of social support may lead to increased psychological distress. In Japan, $45.8 \%$ of employees indicated that interpersonal problems are their primary stressor ${ }^{12)}$. This suggests that it is important that SMT programs should focus not only on improving behavioral and cognitive coping skills, but also interpersonal relationships (e.g., increasing social support).

Notably, in the current research, we examined the effects of our intervention on both the negative (i.e., psychological distress) and positive aspects of psychological well-being (i.e., work engagement, job satisfaction, and work performance). Psychology has recently been criticized as primarily dedicated to addressing mental illness rather than mental "well-being". Since the turn of the century, however, a new trend toward "positive psychology" has emerged. Positive psychology focuses on human strengths and optimal functioning rather than on weakness and malfunctioning ${ }^{13)}$. This shift found in mainstream psychology is also relevant for occupational health psychology. In recent years, results of SMT programs included not only negative outcomes, such as depression, psychological distress, and anxiety ${ }^{5,14)}$, but also positive outcomes such as job satisfaction ${ }^{15,16)}$, work performance ${ }^{17,18)}$, vitality ${ }^{19)}$, and propensity to innovate ${ }^{16)}$.

Although empirical evidence that supports the effectiveness of individual-focused SMT is accumulating, the workplace still has a number of barriers that impede access to mental health activities, such as "lack of experts" and "lack of knowledge about how to address mental health services"12). Computer-based self-help programs may be an effective and inexpensive alternative to traditional faceto-face SMT programs. For instance, Shimazu et al. ${ }^{20)}$ investigated the effectiveness of a computer-based psychoeducational program for workers. They found that participants in the intervention group experienced improvements in self-efficacy and job satisfaction. Another study by Eisen $e t a l .{ }^{21)}$ investigating the relative effectiveness of a live versus computer guidance group, showed that the computer guidance group was similar to the live guidance group in terms of the frequency with which participants practiced their skills ${ }^{21)}$. Furthermore, computer-based selfhelp programs can be used as tools to compensate for the lack of experts and knowledge in the workplace on how to address mental health services among occupational health staff. However, few studies have investigated the positive aspects of computer-based SMT program outcomes using rigorous study designs such as a randomized controlled trial.

The purpose of this study is to develop a computerbased SMT program and evaluate its effectiveness on employees' psychological well-being (i.e., (lower) psychological distress, work engagement, and job satisfaction), and work performance. We hypothesized that our computer-based SMT program would improve employees' psychological resources (i.e., coping skills, social support, and knowledge about stress management as secondary outcomes) and consequently their psychological wellbeing (i.e., (lower) psychological distress, work engagement, and job satisfaction) and work performance.

\section{Methods}

\section{Participants}

This study was conducted as a mental health promotion program in a manufacturing company. In total, 12 work units from the research and development divisions and support staff $(N=266)$ were invited to participate in the study. All participants were full-time employees. Participants were informed about the program by an informational poster as well as their supervisor during meetings. Participants were randomly assigned by work unit ${ }^{22)}$ to either an intervention or wait-list control group to participate in a computer-based SMT program. No inclusion or exclusion criteria were adopted because the intervention was planned for all employees in the research and development divisions. All employees participated, with the exception of one individual who was responsible for coordinating study-related details between the company and the author of this paper and another who changed workplaces prior to completing the baseline survey.

\section{Design}

The study was a cluster randomized controlled trial. In May 2009, a baseline survey (T0) was conducted, and then participants were randomly assigned by work unit to a computer-based intervention group ( 8 work units, 
$n=142$ ) or a wait-list control group (4 work units, $n=121$ ). Additionally, participants were required to answer online questionnaires at 9 weeks (T1) and 19 weeks (T2) after the baseline survey. The timing of these questionnaires were selected based on recommendations in a metaanalysis conducted by van der Klink ${ }^{5)}$. Specifically, van der Klink recommends a minimum of 12 weeks between baseline surveys and follow-up questionnaires since health outcomes are more stable than coping skills ${ }^{8}$. The intervention group started the 7 -week program immediately after the baseline survey, while the wait-list control group started after the T2 follow-up survey.

\section{Intervention program}

A computer-based SMT program was developed using the following 3 steps: 1) literature review, 2) trial survey, and 3) modification. First, a trial program was developed based on results from past stress management training research $^{18)}$. Next, a pilot trial, consisting of 19 employees who worked in laboratory or administration department, was conducted at a research institute in September 2008. Lastly, after implementing revisions based on participants' feedback $(n=11)$, the final version of the program was completed.

The computer-based SMT program was self-paced and consisted of the following: 1) behavioral techniques, 2) communication techniques, and 3) cognitive techniques. Additionally, each part was divided into 2 topics on the basis of cognitive behavioral skills: (a) problem-solving and time management skills for the behavioral techniques section, (b) assertion and delegation skills for the communication techniques section, and (c) cognitive restructuring and causal attribution skills for the cognitive techniques section.

Participants learned these skills in a 2-phased approach, which consisted of a skill acquisition phase and a practice phase. The skill acquisition phase focused on improving participants' understanding of each skill. Through selfmonitoring, participants learned which skills they lacked. The practice phase focused on encouraging participants to put the skills they acquired to practice in their everyday life. Participants could enter any problems or experiences they encountered on their own private web page to help resolve them. According to social learning theory, selfefficacy beliefs (judgments regarding one's capabilities) and outcome expectancies (judgments regarding the consequences of behaviors) significantly influence coping behaviors ${ }^{23)}$. The goal of the skill acquisition phase was to increase participants' 'outcome expectancies' about intervention related outcomes, and the goal of the practice phase was to increase 'efficacy expectancy'.

\section{Learning procedure}

One of the office staff served as the coordinator between the participants and author of the present work. Participants in both groups were given individual IDs and passwords before starting the program. Participants underwent the program during working hours. Communication between participants and the author took place entirely through e-mail without any face-to-face interaction. Considering that the average length of the stress management intervention program was 7.4 weeks $^{14)}$ and that our program consisted of six lessons, an optimal pace of one lesson per week was chosen. Hence, participants received an email every week during the time course of the intervention. To increase participants' motivation and decrease dropout rates, the following 3 types of e-mails served as reminders or prompts: 1) an "encouragement email" for participants who had not finished all 6 topics, 2) a "congratulations e-mail" for participants who finished all topics for the first time, and 3) an "application enhancement e-mail" for participants who finished all topics and were ready for skills phase. These e-mails were sent to participants through the coordinator every week throughout the intervention.

\section{Measurements}

All data were assessed using self-report questionnaires, and all questionnaires were administered on the internet. Questionnaires, as well as the learning program, were only accessible with an ID and password. Details of the scales and questions used in the study are described below.

\section{Primary outcomes}

Psychological distress was assessed using the 18-item Brief Job Stress Questionnaire (BJSQ) ${ }^{24)}$ measuring the extent to which participants experienced irritability-anger, fatigue (e.g., "I am completely tired"), anxiety (e.g., "I feel ill at ease"), depression (e.g., "I feel depressed"), and lack of vigor in the four weeks prior. Items were scored on a 4-point scale ranging from 1 (strongly disagree) to 4 (strongly agree). Higher scores indicated greater psychological distress.

Job satisfaction was assessed using a single item of the $\mathrm{BJSQ}^{24)}$ assessing the extent to which participants were satisfied with their job. This item was scored on a 4-point scale ranging from 1 (dissatisfied) to 4 (satisfied). Higher scores indicated greater job satisfaction. 
Work engagement was assessed using the short form of the Japanese version of the Utrecht Work Engagement Scale (UWES-J) ${ }^{25}$. The UWES-J consists of 3 subscales with 9 items (i.e., vigor, dedication, absorption). Items were scored on a 7-point scale ranging from 0 (never) to 6 (always). Item examples were "At my job, I feel strong and vigorous" (vigor), "I am enthusiastic about my job" (dedication), and "I am immersed in my work" (absorption). A total score was calculated using all 9 items. Higher scores indicated greater work engagement.

Work performance was assessed using the World Health Organization (WHO) Health and Work Performance Questionnaire (HPQ) ${ }^{26,27)}$. The HPQ includes items assessing the following: quantitative and qualitative work efficiency over the previous $30 \mathrm{~d}$ (10 items), self-evaluated job outcomes relative to other workers ( 1 item), and special work success or failure over the past $30 \mathrm{~d}$ ( 2 items). Due to the space limitation, one item was removed from the HPQ (i.e., self-evaluated job outcomes relative to those of other workers). Participants were also asked to rate their overall work performance over the past 4 weeks. This item was scored using an 11-point scale ranging from 0 (worst possible performance) to 10 (best possible performance). Higher scores indicated greater perceived work performance.

\section{Secondary outcomes}

Coping skills were assessed using a subscale taken from the Brief Scales for Coping Profile $(\mathrm{BSCP})^{28)}$. The BSCP consists of 6 subscales containing 18 items (i.e., active solution, seeking help for solution, changing mood, emotional expression involving others, avoidance and suppression, and changing point of view). Participants were asked to indicate the extent to which they used a particular strategy for coping with stressful workplace situations using a scale that ranged from 1 (almost never) to 4 (very often). The current study used an "active solution" scale for problem solving and a "seeking help for solution" scale for seeking social support. Examples were "I try to analyze the cause and solve the problem" (problem solving), "I try to solve the problem by talking to those involved in the matter" (seeking social support), "I try to do something that calms me down" (changing mood), "I complain to people who have nothing to do with the problem" (emotional expression involving others), "I do nothing but endure the situation because I don't know what to do" (avoidance and suppression), and "I try to look at only the positive aspects of the situation" (changing a point of view). Higher scores reflected more frequent use of the indicated coping strategy.

Social support was assessed using 6 items of the $\mathrm{BJSQ}^{24)}$. Items were scored on a 4 -point scale ranging from 1 (disagree) to 4 (agree). Three items were used to assess social support from participants' supervisors and another three items assessed social support from coworkers (e.g., "How much is each of the following people willing to listen to your personal problems?"). Higher scores indicated greater support.

Knowledge about how to cope with stress was assessed using 6 questions on the following topics: (a) problemsolving skills, (b) time management skills, (c) assertion skills, (d) delegation skills, (e) cognitive restructuring skills, and (f) causal attribution skills. Participants were asked to choose the most suitable option among 4 skills presented. A score of 1 was given for a correct answer. To assess the reliability and validity of this measurement, 2 analyses were conducted. First, using T0 and T1 scores from the wait-list control group, a weighted kappa statistic was calculated $(K=0.49)$. Next, the correlation between "the minimum number of days participants log onto a website to study the contents" and "knowledge about stress management" was assessed for the intervention group (T0 to T1 $r=0.13, p>0.05$; T0 to T2 $r=0.16, p=0.06$ ).

\section{Covariates}

Job demands were assessed by using 3-item subscales of the $\mathrm{BJSQ}^{24)}$. Items were scored on a 4-point selfanchoring scale ranging from 1 (strongly disagree) to 4 (strongly agree). An item example was "My job requires working hard." High scale scores indicated a high extent of Job demands.

\section{Demographic data}

Demographic data such as sex, age, and job position were also collected using the questionnaire.

\section{Sample Size Calculation}

The statistical power analysis was conducted using the $\mathrm{G}^{*}$ Power 3 program $^{29)}$. We calculated sample size with a method that takes into account the intracluster correlation coefficient (ICC) ${ }^{30)}$. We assumed an intracluster correlation of $\rho=0.2,15$ participants for each unit. To prove an intervention effect with an effect size of Cohen's $d=0.4$ (we decided effect size from our previous study ${ }^{18)}$ ) and with an error probability $\alpha=0.05$ and $80 \%$ power, $n=128$ people in each study arm were required for analysis. 


\section{Statistical Analyses}

All data were analyzed using Statistical Package for the Social Sciences (SPSS) version 18.0 J. Baseline characteristics of the intervention and wait-list control groups were compared and tested using $t$-tests for continuous data comparisons and $\chi^{2}$ tests for ordinal or categorical data comparisons. Furthermore, using the T0 data from the intervention group, we also compared baseline characteristics between "completers", or participants who completed all six contents and answered all T0, T1 and T2 questionnaires, and "non-completers", or participants who answered the T0 questionnaire but (1) did not complete all the contents and (2) did not answer the T1 and/or T2 questionnaires.

To assess the effects of the intervention on the primary and secondary outcomes, a group $\times$ time interaction was tested using a mixed-model approach employing a repeated-measures ANOVA and the restricted maximum likelihood (REML) estimation method. We included time and group as fixed factors and subject as a nested within unit random factor. The within-subjects factor was "time" and the between-subjects factor was "group". Job demands were included in the model as a covariate. When the group $\times$ time interaction was interpreted as significant, time simple main effect was computed for each group. In addition, paired $t$-test for $\mathrm{T} 0$ to $\mathrm{T} 1$ and $\mathrm{T} 0$ to $\mathrm{T} 2$ were used to test the differences. The effect size (Cohen's $d$ ) was also calculated as a standardized measure of change ${ }^{31)}$. Cohen suggested the values of $d$ equal to $0.20,0.50$, and 0.80 as small, medium, and large effect sizes, respectively. Since multiple comparisons were made, the Bonferroni correction was applied to control for increased probability of Type 1 errors or spurious results. Using the Bonferroni procedure, statistical significance was reduced from 0.05 to $0.0038(0.05 / 13)$.

We conducted additional analyses. First, we assessed intervention effects excluding participants in the "dashed study group," which referred to participants that (1) did not finished all 6 topics, (2) had finished the program in one day, or (3) had joined the program $2 \mathrm{~d}$ before the study deadline. Even though our program allows for a short learning time (1 topic per approximately $30 \mathrm{~min}$ ), one or two days was not enough time to finish our computerbased SMT program during working hours. It is important to note that participants in the intervention group were divided into two groups by the median number of days they spent studying.

Secondly, we conducted the sub-group analysis according to the level of psychological distress at T0. In this sub-group analysis, participants were divided into one of two groups using a median split. Using this approach we examined whether psychological distress moderated the effects of the intervention. We performed this analysis because past work $^{32)}$ has suggested that the effects of an SMT program are more prominent among employees experiencing high psychological distress.

\section{Ethics}

The study procedure was approved by the Research Ethics Review Board of the University of Tokyo, Graduate School of Medicine.

\section{Results}

\section{Participant flow}

A summary of participant flow and retention is shown in Fig. 1. A total of 266 participants were invited to participate in the study and 263 participants were met eligibility requirements and included in the analysis. Of the $142 \mathrm{em}-$ ployees in the intervention group, 127 participants (89\%) completed all 6 topics, and 16 employees (11\%) did not finish it. Of the 16 employees, 1 employee discontinued the program because he/she retired during the course of the study. The remaining 15 employees did not specify the reason they did not complete the program. One hundred and sixteen participants who completed all six contents and answered all measures at T0, T1 and T2. One hundred and thirteen $(80 \%)$ participants in the intervention group first learned problem solving skills and then time management skills.

\section{Baseline characteristics}

Demographic characteristics and outcome variables at baseline for the intervention and wait-list control groups are presented in Tables 1 and 2. Although the intervention group had significantly higher scores on work engagement compared to the wait-list control group $(t=-2.2, p=0.00)$, no other significant differences were found between the groups $(p>0.05)$.

\section{Dropout analysis}

Baseline characteristics between completers $(n=116)$ and non-completers $(n=26)$ in the intervention group were compared. Non-completers had significantly higher psychological distress scores $(t=2.04, p=0.043)$ and lower scores for seeking social support $(t=-2.63, p=0.009)$ and changing a point of view compared to completers $(t=-2.70$, $p=0.008$ ). However, we detected no differences between 


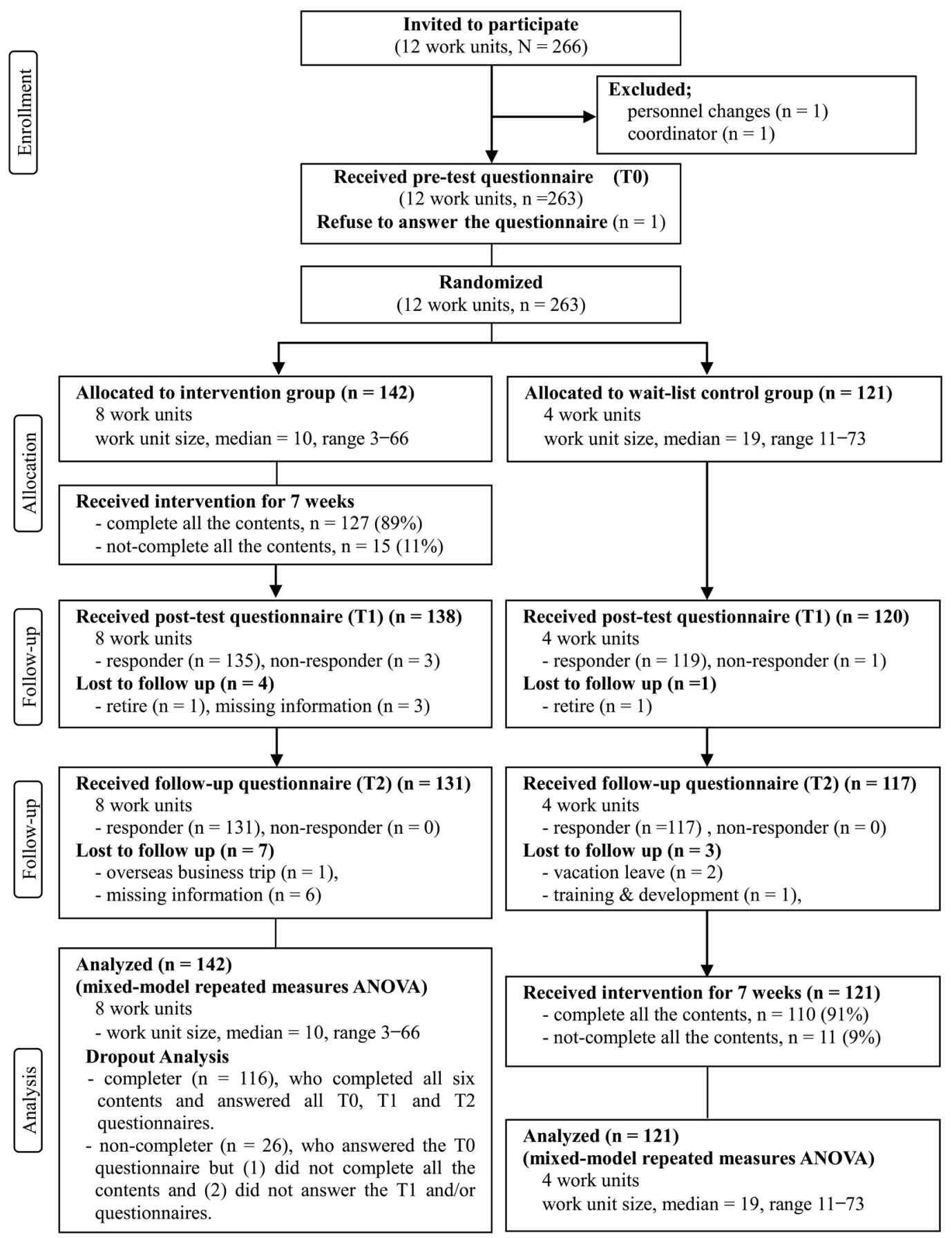

Fig. 1. Enrollment, random assignment, and follow-up of the participants.

the groups in any of the other variables $(p>0.05)$.

\section{Effects of the intervention}

The effects of the intervention on the primary and secondary outcome measures are presented in Table 3. A repeated-measures mixed-model ANOVA revealed a statistically significant group $\times$ time interaction on knowledge about stress management $(F=6.028, p=0.003)$. The simple main effect of time on knowledge was significant for both the intervention and wait-list control groups $(F=7.785$, $p=0.001 ; F=4.003, p=0.020$, respectively). Knowledge scores significantly increased from $\mathrm{T} 0$ to $\mathrm{T} 1$ in intervention group $(p<0.001)$ and significantly decreased from T0 to T2 in the wait-list control group $(p=0.023)$. However, 
Table 1. Demographic characteristics by condition

\begin{tabular}{lccl}
\hline & Intervention & Wait-list control & \\
\hline Group factors at baseline & & & \\
$\quad \mathrm{N}$ & 8 & 4 & \\
$\quad$ List size & & & \\
$\quad$ Low $(<20)$ & 6 & 2 & \\
$\quad$ High $(\geq 20)$ & 2 & 21 & \\
Individual factors at baseline & & & \\
n & 142 & 121.0 & n.s. $\dagger$ \\
Age (mean) & 39.7 & $109(90.1)$ & n.s. \\
n of male $(\%)$ & $135(95.1)$ & $24(19.8)$ & n.s. \\
$\quad$ n of manager $(\%)$ & $37(26.1)$ & & \\
\hline
\end{tabular}

$\dagger$ n.s. indicates no significant $(p>0.05)$

Table 2. Baseline characteristics by conditfion and intracluster correlation coefficients (ICC) of primary outcome

\begin{tabular}{|c|c|c|c|c|c|c|}
\hline \multirow[t]{2}{*}{ Valuables } & \multicolumn{2}{|c|}{$\begin{array}{l}\text { Intervention } \\
\quad(n=142)\end{array}$} & \multicolumn{2}{|c|}{$\begin{array}{l}\text { Wait-list control } \\
\qquad(n=121)\end{array}$} & \multirow[t]{2}{*}{$p$ value } & \multirow[t]{2}{*}{ ICC } \\
\hline & Mean & (SD) & Mean & (SD) & & \\
\hline \multicolumn{7}{|l|}{ Primary outcome } \\
\hline Psychological distress & 2.0 & $(0.56)$ & 2.0 & $(0.48)$ & 0.157 & 0.032 \\
\hline Work performance & 5.5 & $(2.02)$ & 5.8 & $(2.01)$ & 0.301 & 0.054 \\
\hline Job satisfaction & 2.9 & $(0.65)$ & 3.0 & $(0.66)$ & 0.100 & 0.008 \\
\hline Work engagement & 2.7 & $(0.92)$ & 3.0 & $(0.91)$ & 0.028 & 0.033 \\
\hline \multicolumn{7}{|l|}{ Secondary outcome } \\
\hline Problem-solving & 2.8 & $(0.78)$ & 2.9 & $(0.76)$ & 0.191 & \\
\hline Seeking social support & 2.5 & $(0.85)$ & 2.7 & $(0.90)$ & 0.132 & \\
\hline Changing mood & 2.8 & $(0.99)$ & 2.8 & $(0.98)$ & 0.978 & \\
\hline Emotional expression involving others & 1.5 & $(0.49)$ & 1.5 & $(0.52)$ & 0.860 & \\
\hline Avoidance and suppression & 2.0 & $(0.69)$ & 1.8 & $(0.67)$ & 0.054 & \\
\hline Changing point of view & 2.4 & $(0.66)$ & 2.5 & $(0.74)$ & 0.125 & \\
\hline Knowledge about stress management & 3.0 & $(0.92)$ & 2.8 & $(0.80)$ & 0.071 & \\
\hline Supervisor support & 2.5 & $(0.62)$ & 2.6 & $(0.59)$ & 0.161 & \\
\hline Coworker support & 2.6 & $(0.58)$ & 2.7 & $(0.56)$ & 0.250 & \\
\hline \multicolumn{7}{|l|}{ Covariate } \\
\hline Job demands & 3.2 & $(0.63)$ & 3.0 & $(0.49)$ & 0.084 & \\
\hline
\end{tabular}

there was no significant group $\times$ time interaction on any of the other variables assessed ( $p>0.05)$. It is important to note that we found small effects of the intervention on measures of work performance (T1, T2), job satisfaction (T1, T2), problem-solving (T1, T2), seeking social support (T1, T2), avoidance and suppression (T2), changing a point of view (T2), supervisor support (T1, T2), and coworker support (T2). However, these effects were not statistically significant.
Additional analyses

In the intervention group, $40 \%$ of participants were met requirements for the "dashed study group". We assessed intervention effects excluding participants in the "dashed study group". In this analysis, there was no significant group $\times$ time interaction on the primary outcome measures $(p>0.05)$. However, a repeated-measures mixed-model ANOVA revealed a group $\times$ time interaction on secondary outcome measures. Specifically, there was a significant group $\times$ time interaction for "problem-solving", "avoidance and suppression", and "knowledge about stress manage- 
Table 3. Comparison of the scores between study conditions by mixed-effects models ANOVA

\begin{tabular}{|c|c|c|c|c|c|c|c|c|c|}
\hline & \multicolumn{2}{|c|}{ T0 } & \multicolumn{2}{|c|}{$\mathrm{T} 1$} & \multicolumn{2}{|c|}{$\mathrm{T} 2$} & \multirow{2}{*}{$p$ value } & \multicolumn{2}{|c|}{ Cohen's $d \dagger$} \\
\hline & Mean & (SD) & Mean & (SD) & Mean & (SD) & & $\mathrm{T} 1$ & $\mathrm{~T} 2$ \\
\hline \multicolumn{10}{|l|}{ Primary outcome } \\
\hline \multicolumn{10}{|l|}{ Psychological distress } \\
\hline Intervention $\S$ & 2.0 & $(0.48)$ & 1.9 & $(0.45)$ & 2.0 & $(0.45)$ & 0.991 & 0.16 & 0.14 \\
\hline Wait-list control $\$$ & 2.1 & $(0.56)$ & 2.0 & $(0.55)$ & 2.0 & $(0.55)$ & & & \\
\hline \multicolumn{10}{|l|}{ Work performance } \\
\hline Intervention & 5.8 & $(2.01)$ & 5.8 & (1.93) & 5.9 & $(1.75)$ & 0.468 & 0.24 & 0.20 \\
\hline Wait-list control & 5.5 & $(2.02)$ & 5.4 & $(1.82)$ & 5.5 & $(1.91)$ & & & \\
\hline \multicolumn{10}{|l|}{ Job satisfaction } \\
\hline Intervention & 3.0 & $(0.66)$ & 3.1 & $(0.60)$ & 3.0 & $(0.57)$ & 0.356 & 0.35 & 0.29 \\
\hline Wait-list control & 2.9 & $(0.65)$ & 2.8 & $(0.64)$ & 2.8 & $(0.65)$ & & & \\
\hline \multicolumn{10}{|l|}{ Work engagement } \\
\hline Intervention & 3.0 & $(0.91)$ & 2.9 & $(0.91)$ & 3.0 & $(0.99)$ & 0.182 & 0.12 & 0.19 \\
\hline Wait-list control & 2.7 & $(0.92)$ & 2.8 & $(0.94)$ & 2.8 & $(0.94)$ & & & \\
\hline \multicolumn{10}{|l|}{ Secondary outcome } \\
\hline \multicolumn{10}{|l|}{ Problem-solving } \\
\hline Intervention & 3.0 & $(0.76)$ & 3.1 & $(0.75)$ & 3.1 & $(0.71)$ & 0.255 & 0.31 & 0.37 \\
\hline Wait-list control & 2.8 & $(0.78)$ & 2.9 & $(0.71)$ & 2.8 & $(0.82)$ & & & \\
\hline \multicolumn{10}{|c|}{ Seeking social support } \\
\hline Intervention & 2.7 & $(0.90)$ & 2.9 & $(0.84)$ & 2.9 & $(0.80)$ & 0.413 & 0.33 & 0.37 \\
\hline Wait-list control & 2.5 & $(0.85)$ & 2.6 & $(0.81)$ & 2.6 & $(0.86)$ & & & \\
\hline \multicolumn{10}{|l|}{ Changing mood } \\
\hline Intervention & 2.8 & $(0.98)$ & 2.6 & $(0.98)$ & 2.7 & $(0.91)$ & 0.521 & 0.13 & 0.02 \\
\hline Wait-list control & 2.8 & $(0.99)$ & 2.7 & $(0.98)$ & 2.7 & $(0.99)$ & & & \\
\hline \multicolumn{10}{|c|}{ Emotional expression involving others } \\
\hline Intervention & 1.5 & $(0.52)$ & 1.6 & $(0.59)$ & 1.6 & $(0.58)$ & 0.696 & 0.05 & 0.09 \\
\hline Wait-list control & 1.5 & $(0.49)$ & 1.6 & $(0.51)$ & 1.6 & $(0.58)$ & & & \\
\hline \multicolumn{10}{|c|}{ Avoidance and suppression } \\
\hline Intervention & 1.8 & $(0.67)$ & 1.8 & $(0.69)$ & 1.8 & $(0.69)$ & 0.104 & 0.18 & 0.46 \\
\hline Wait-list control & 2.0 & $(0.69)$ & 2.0 & $(0.72)$ & 2.1 & $(0.79)$ & & & \\
\hline \multicolumn{10}{|c|}{ Changing a point of view } \\
\hline Intervention & 2.5 & $(0.74)$ & 2.5 & $(0.62)$ & 2.6 & $(0.72)$ & 0.891 & 0.19 & 0.26 \\
\hline Wait-list control & 2.4 & $(0.66)$ & 2.4 & $(0.65)$ & 2.4 & $(0.65)$ & & & \\
\hline \multicolumn{10}{|c|}{ Knowledge about stress management } \\
\hline Intervention & 2.8 & $(0.80)$ & 3.2 & $(0.88)$ & 3.0 & $(0.88)$ & 0.003 & 0.19 & 0.19 \\
\hline Wait-list control & 3.0 & $(0.92)$ & 3.0 & $(0.84)$ & 2.8 & $(0.81)$ & & & \\
\hline \multicolumn{10}{|l|}{ Supervisor support } \\
\hline Intervention & 2.6 & $(0.59)$ & 2.7 & $(0.55)$ & 2.7 & $(0.61)$ & 0.546 & 0.23 & 0.26 \\
\hline Wait-list control & 2.5 & $(0.62)$ & 2.5 & $(0.60)$ & 2.5 & $(0.61)$ & & & \\
\hline \multicolumn{10}{|l|}{ Coworker support } \\
\hline Intervention & 2.7 & $(0.56)$ & 2.7 & $(0.52)$ & 2.7 & $(0.58)$ & 0.562 & 0.17 & 0.29 \\
\hline Wait-list control & 2.6 & $(0.58)$ & 2.6 & $(0.54)$ & 2.6 & $(0.54)$ & & & \\
\hline
\end{tabular}

Means and standard deviation (SD) are reported for each primary and secondary outcome at baseline (T0), 9 (T1) and 19 (T2) weeks of follow-up. $p$-values are based on mixed-model repeated measures ANOVA. Job demands were adjusted for in the model. $\dagger$ Cohen's $d$ : Small effect $0.20-0.49$, medium effect $0.50-0.79$, large effect $>0.80^{10)}$. Intervention group $(n=85) \S$ Wait-list control group $(n=121)$

ment" $(F=5.029, p=0.007 ; F=3.171, p=0.043 ; F=7.819$, ally significant group $\times$ time interaction for "seeking social $p<0.001$, respectively). Furthermore, there was a marginsupport" $(F=2.784, p=0.063)$. However, there was no sig- 
nificant group $\times$ time interaction for any other secondary outcomes $(p>0.05)$.

The simple main effects of time on "problem-solving" and "seeking social support" were statistically significant ( $F=9.668, p<0.001 ; F=6.273, p=0.002$, respectively) for the intervention group only. For the intervention group, "problem-solving" and "seeking social support" scores significantly increased from T0 to T1 $(p=0.002 ; p<0.001$, respectively) and from T0 to T2 ( $p=0.004 ; p=0.007$, respectively). The simple main effect of time on "avoidance and suppression" was marginally significant $(F=2.520$, $p=0.083$, respectively) for the wait-list control group. The simple main effect of time on "knowledge about stress management" was significant for both the intervention and wait-list control groups $(F=8.087, p<0.001 ; F=4.003$, $p=0.020$, respectively). Knowledge scores significantly increased from T0 to T1 $(p<0.001)$ and from T0 to T2 in the intervention group $(p=0.035)$. Conversely, knowledge scores significantly decreased from $\mathrm{T} 0$ to $\mathrm{T} 2$ for the waitlist control group ( $p=0.023$ ) (Table 4).

Next, we conducted a sub-group analysis according to level of psychological distress at T0. Among participants with low initial psychological distress levels, a repeatedmeasures mixed-model ANOVA revealed a significant group $\times$ time interaction on "knowledge about stress management" $(F=5.186, p=0.006)$. However, results did not show a significant group $\times$ time interaction on any other variables $(p>0.05)$. The simple main effect of time on "knowledge about stress management" was statistically significant for both the intervention and wait-list control groups $(F=4.698, p=0.011 ; F=8.789, p<0.001$, respectively). Knowledge scores significantly increased from $\mathrm{T} 0$ to $\mathrm{T} 1$ among participants in the intervention group $(p=0.008)$ and significantly decreased from T0 to $\mathrm{T} 2$ among participants in the wait-list control group $(p<0.001)$. In contrast, among participants with high initial psychological distress levels, a repeated-measures mixedmodel ANOVA revealed a marginally significant group $\times$ time interaction on "seeking social support" $(F=2.863$, $p=0.059)$. However, there was no group $\times$ time interaction on any other variables $(p>0.05)$. The simple main effect of time on "seeking social support" was significant for the intervention group $(F=5.459, p=0.005)$. For participants in the intervention group, "seeking social support" scores significantly increased from T0 to T1 $(p=0.019)$ and T0 to T2 $(p=0.006)$.

\section{Discussion}

The purpose of this study was to develop a computerbased SMT program and to evaluate its effectiveness on employees' psychological resources and well-being. We used a cluster randomization design that assigned employees to intervention and control groups by work unit. One advantage of this design was that it prevented participants from finding out about the contents of the program ${ }^{33)}$. If individual allocation had been used for this study, participants in the control group might have been affected by interactions with their colleagues in the intervention group. Furthermore, in contrast to previous interventions, which have typically focused on a single topic ${ }^{20,34-36)}$, the current work employed a computer-based SMT program that assessed a wider variety of topics on stress management skills.

The completion rate, or the ratio of participants who completed the whole program, was higher in the current research (89 and $92 \%$ for the intervention and wait-list control groups, respectively) compared to previous studies $(76-86 \%)^{20,34,37)}$. In addition, a manager in the intervention group requested permission to use the materials for future management training of his subordinates. These results suggest that the contents and procedures used in the current intervention were accepted by the participants.

Dropout analyses revealed that employees with high initial levels of "psychological distress" tended to drop out throughout the study. This result is in line with previous research showing that stressed employees are more likely to drop out than their non-stressed counterparts ${ }^{32)}$.

Contrary to our expectations, we found a favorable effect of the intervention only on "knowledge about stress management" at $\mathrm{T} 1$ but not on any other primary or secondary outcomes at $\mathrm{T} 1$ and $\mathrm{T} 2$. In our study, $40 \%$ of participants (i.e., dashed study group) finished the program in 1 or $2 \mathrm{~d}$, and almost all of them accessed the program $2 \mathrm{~d}$ before the deadline for the first time. This suggests that they did not have enough time to incorporate their newly acquired knowledge and skills into their everyday life. Previous research has shown that more frequent use of stress-reduction skills are significantly correlated with greater improvements in stress related outcomes ${ }^{21)}$. Hence, more time would have been necessary for participants to show improvements on all other outcomes variables except for knowledge. This explanation is bolstered by the finding that the intervention produced favorable effects not only on participants' knowledge but also on coping skills (i.e., problem-solving, and seeking social support) 
Table 4. Comparison of the scores between study conditions excluding participants who used less than $3 \mathrm{~d}$ to complete the program by mixed-effects ANOVA models

\begin{tabular}{|c|c|c|c|c|c|c|c|c|c|}
\hline & \multicolumn{2}{|c|}{ T0 } & \multicolumn{2}{|c|}{$\mathrm{T} 1$} & \multicolumn{2}{|c|}{$\mathrm{T} 2$} & \multirow{2}{*}{$p$ value } & \multicolumn{2}{|c|}{ Between-ES $\dagger$} \\
\hline & Mean & (SD) & Mean & $(\mathrm{SD})$ & Mean & (SD) & & $\mathrm{T} 1$ & $\mathrm{~T} 2$ \\
\hline \multicolumn{10}{|l|}{ Primary outcome } \\
\hline \multicolumn{10}{|l|}{ Psychological distress } \\
\hline Intervention $\$$ & 2.0 & $(0.47)$ & 1.9 & $(0.42)$ & 2.0 & $(0.41)$ & 0.820 & 0.22 & 0.12 \\
\hline Wait-list control $\S$ & 2.0 & $(0.56)$ & 2.0 & $(0.55)$ & 2.0 & $(0.55)$ & & & \\
\hline \multicolumn{10}{|l|}{ Work performance } \\
\hline Intervention & 5.8 & $(1.90)$ & 5.8 & $(1.82)$ & 5.8 & $(1.64)$ & 0.646 & 0.23 & 0.16 \\
\hline Wait-list control & 5.5 & $(2.02)$ & 5.4 & $(1.82)$ & 5.5 & $(1.91)$ & & & \\
\hline \multicolumn{10}{|l|}{ Job satisfaction } \\
\hline Intervention & 3.0 & $(0.70)$ & 3.0 & $(0.58)$ & 3.0 & $(0.53)$ & 0.302 & 0.34 & 0.24 \\
\hline Wait-list control & 2.9 & $(0.65)$ & 2.8 & $(0.64)$ & 2.8 & $(0.65)$ & & & \\
\hline \multicolumn{10}{|l|}{ Work engagement } \\
\hline Intervention & 2.9 & $(0.87)$ & 2.8 & $(0.84)$ & 2.9 & $(0.85)$ & 0.467 & 0.08 & 0.16 \\
\hline Wait-list control & 2.7 & $(0.92)$ & 2.8 & $(0.94)$ & 2.8 & $(0.94)$ & & & \\
\hline \multicolumn{10}{|l|}{ Secondary outcome } \\
\hline \multicolumn{10}{|l|}{ Problem-solving } \\
\hline Intervention & 2.9 & $(0.76)$ & 3.1 & $(0.76)$ & 3.2 & $(0.67)$ & 0.007 & 0.34 & 0.48 \\
\hline Wait-list control & 2.8 & $(0.78)$ & 2.9 & $(0.71)$ & 2.8 & $(0.81)$ & & & \\
\hline \multicolumn{10}{|c|}{ Seeking social support } \\
\hline Intervention & 2.7 & $(0.89)$ & 2.9 & $(0.76)$ & 2.9 & $(0.80)$ & 0.063 & 0.46 & 0.42 \\
\hline Wait-list control & 2.5 & $(0.85)$ & 2.6 & $(0.81)$ & 2.6 & $(0.86)$ & & & \\
\hline \multicolumn{10}{|l|}{ Changing mood } \\
\hline Intervention & 2.8 & $(0.98)$ & 2.5 & $(1.00)$ & 2.7 & $(0.89)$ & 0.481 & 0.16 & 0.00 \\
\hline Wait-list control & 2.8 & $(0.99)$ & 2.7 & $(0.98)$ & 2.7 & $(0.99)$ & & & \\
\hline \multicolumn{10}{|c|}{ Emotional expression involving others } \\
\hline Intervention & 1.4 & $(0.39)$ & 1.6 & $(0.51)$ & 1.5 & $(0.45)$ & 0.245 & 0.00 & 0.04 \\
\hline Wait-list control & 1.5 & $(0.49)$ & 1.6 & $(0.51)$ & 1.6 & $(0.58)$ & & & \\
\hline \multicolumn{10}{|c|}{ Avoidance and suppression } \\
\hline Intervention & 1.9 & $(0.62)$ & 1.8 & $(0.67)$ & 1.7 & $(0.62)$ & 0.043 & 0.22 & 0.54 \\
\hline Wait-list control & 2.0 & $(0.69)$ & 2.0 & $(0.72)$ & 2.1 & $(0.79)$ & & & \\
\hline \multicolumn{10}{|c|}{ Changing a point of view } \\
\hline Intervention & 2.5 & $(0.75)$ & 2.5 & $(0.62)$ & 2.6 & $(0.68)$ & 0.957 & 0.25 & 0.27 \\
\hline Wait-list control & 2.4 & $(0.66)$ & 2.4 & $(0.65)$ & 2.4 & $(0.65)$ & & & \\
\hline \multicolumn{10}{|c|}{ Knowledge about stress management } \\
\hline Intervention & 2.8 & $(0.83)$ & 3.3 & $(0.82)$ & 3.1 & $(0.85)$ & 0.000 & 0.33 & 0.34 \\
\hline Wait-list control & 3.0 & $(0.92)$ & 3.0 & $(0.84)$ & 2.8 & $(0.81)$ & & & \\
\hline \multicolumn{10}{|l|}{ Supervisor support } \\
\hline Intervention & 2.6 & $(0.60)$ & 2.6 & $(0.58)$ & 2.6 & $(0.62)$ & 0.417 & 0.17 & 0.24 \\
\hline Wait-list control & 2.5 & $(0.62)$ & 2.5 & $(0.60)$ & 2.5 & $(0.61)$ & & & \\
\hline \multicolumn{10}{|l|}{ Coworker support } \\
\hline Intervention & 2.7 & $(0.59)$ & 2.7 & $(0.51)$ & 2.7 & $(0.54)$ & 0.299 & 0.13 & 0.31 \\
\hline Wait-list control & 2.6 & $(0.58)$ & 2.6 & $(0.54)$ & 2.6 & $(0.54)$ & & & \\
\hline
\end{tabular}

Means and standard deviation (SD) are reported for each primary and secondary outcome at baseline (T0), 9 (T1) and 19 (T2) weeks of followup. $p$-values are based on mixed-model repeated measures ANOVA. Job demands were adjusted for in the model. $\dagger$ Cohen's $d$ : Small effect $0.20-0.49$, medium effect $0.50-0.79$, large effect $>0.80^{10)}$. $\$$ Intervention group $(n=85)$. $\S$ Wait-list control group $(n=121)$

at $\mathrm{T} 1$ and $\mathrm{T} 2$ (when excluding data from the dashed-study group). More frequent use of problem-solving and support- seeking skills in participants' daily lives may have led to these improvements. Nevertheless, it should be noted that, 
while not statistically significant, our program had small effects on outcome variables (i.e., work performance, job satisfaction, problem-solving, seeking social support, and supervisor support). It was hypothesized that the intervention would improve participants' self-efficacy; however, our findings suggest that in spite of the intervention, participants were not able to incorporate their newly learned skills into the work setting. This failure may, in turn, have caused a reduction of self-efficacy. As such, the practical phase of this intervention may benefit from more intensive follow-up sessions aimed at teaching participants how to apply their newly learned skills to work setting scenarios.

Despite the methodological rigor of the present study, there are five limitations that should be addressed in future research. The first limitation has to do with the sample characteristics. Specifically, all participants in the study were employees at a manufacturing company, most of whom were men. Therefore, this population is not representative of the general working population. The second limitation is that our computer-based SMT program consisted of 6 topics, but we did not examine the effect of order on any outcome measures. Future research is needed to clarify whether there is an effect of order on program learning. The third limitation is that outcome measures were only assessed via self-report. Self-reported data could increase the problem of common method variance. Objective indicators on physical health (e.g., urinary cortisol, salivary cortisol, blood pressure, heart rate) and work performance (e.g., personnel evaluation) should also be assessed in future work. The fourth limitation is that no specific indications of how long it took for the intervention effect to appear or disappear were found. Although there is some evidence showing that without booster sessions, the effectiveness of similar interventions diminishes after 6 months $^{38)}$, more research is still needed. The fifth limitation pertains to the clinical/practical significance of the current research findings. Specifically, the observed changes between baseline and the follow-up sessions for the control and intervention groups are unclear due to lack of previous evidence and quantitative information. Additional studies on the effects of web-based psychoeducation are needed to assess the clinical/practical significance of the effect of this kind of intervention on changes in the outcomes of interest.

In conclusion, the computer-based stress management program was effective in improving knowledge about stress management. Among participants that had enough time (at least $3 \mathrm{~d}$ ) to complete all training sessions, the intervention was also effective at improving coping skills.

\section{References}

1) Taylor SE (1991) Health psychology. McGraw-Hill, New York.

2) Bunce D (1997) What factors are associated with the outcome of individual-focused worksite stress management interventions? J Occup Organ Psychol 70, 1-17. [CrossRef]

3) Murphy LR (1996) Stress management in work settings: a critical review of the health effects. Am J Health Promot 11, 112-35. [Medline] [CrossRef]

4) Kawakami N, Haratani $T$, Iwata N, Imanaka $Y$, Murata $K$, Araki S (1999) Effects of mailed advice on stress reduction among employees in Japan: a randomized controlled trial. Ind Health 37, 237-42. [Medline] [CrossRef]

5) van der Klink JJ, Blonk RW, Schene AH, van Dijk FJ (2001) The benefits of interventions for work-related stress. Am J Public Health 91, 270-6. [Medline] [CrossRef]

6) de Vente W, Kamphuis JH, Emmelkamp PM, Blonk RW (2008) Individual and group cognitive-behavioral treatment for work-related stress complaints and sickness absence: a randomized controlled trial. J Occup Health Psychol 13, 214-31. [Medline] [CrossRef]

7) Lazarus R, Folkman S (1984) Stress, appraisal, and coping. Springer Publishing Company, Springer Publishing Company.

8) Shimazu A, Umanodan R, Schaufeli WB (2006) Effects of a brief worksite stress management program on coping skills, psychological distress and physical complaints: a controlled trial. Int Arch Occup Environ Health 80, 60-9. [Medline] [CrossRef]

9) de Jong GM, Emmelkamp PMG (2000) Implementing a stress management training: comparative trainer effectiveness. J Occup Health Psychol 5, 309-20. [Medline] [CrossRef]

10) Kawaharada M, Yoshioka E, Saijo Y, Fukui T, Ueno T, Kishi R (2009) The effects of a stress inoculation training program for civil servants in Japan: a pilot study of a non-randomized controlled trial. Ind Health 47, 173-82. [Medline] [CrossRef]

11) Leiter MP, Maslach C (1999) Six areas of worklife: a model of the organizational context of burnout. J Health Hum Serv Adm 21, 472-89. [Medline]

12) Japanese Ministry of Health, Labour and Welfare (2007) Survey on state of employees' health.

13) Schaufeli W (2004) The future of occupational health psychology. Appl Psychol 53, 502-17. [CrossRef]

14) Richardson KM, Rothstein HR (2008) Effects of occupational stress management intervention programs: a meta-analysis. J Occup Health Psychol 13, 69-93. [Medline] [CrossRef]

15) Mackenzie CS, Poulin PA, Seidman-Carlson R (2006) A brief mindfulness-based stress reduction intervention for nurses and nurse aides. Appl Nurs Res 19, 105-9. [Medline] [CrossRef]

16) Bond FW, Bunce D (2000) Mediators of change in emotion- 
focused and problem-focused worksite stress management interventions. J Occup Health Psychol 5, 156-63. [Medline] [CrossRef]

17) Peters RK, Benson H, Porter D (1977) Daily relaxation response breaks in a working population: I. Effects on selfreported measures of health, performance, and well-being. Am J Public Health 67, 946-53. [Medline] [CrossRef]

18) Umanodan R, Kobayashi Y, Nakamura M, KitaokaHigashiguchi K, Kawakami N, Shimazu A (2009) Effects of a worksite stress management training program with six short-hour sessions: a controlled trial among Japanese employees. J Occup Health 51, 294-302. [Medline] [CrossRef]

19) Atlantis E, Chow CM, Kirby A, Singh MF (2004) An effective exercise-based intervention for improving mental health and quality of life measures: a randomized controlled trial. Prev Med 39, 424-34. [Medline] [CrossRef]

20) Shimazu A, Kawakami N, Irimajiri H, Sakamoto M, Amano S (2005) Effects of web-based psychoeducation on selfefficacy, problem solving behavior, stress responses and job satisfaction among workers: a controlled clinical trial. J Occup Health 47, 405-13. [Medline] [CrossRef]

21) Eisen K, Allen G, Bollash M, Pescatello L (2008) Stress management in the workplace: a comparison of a computerbased and an in-person stress-management intervention. Comput Human Behav 24, 486-96. [CrossRef]

22) Altman DG, Bland JM (1999) How to randomise. BMJ 319, 703-4. [Medline] [CrossRef]

23) Bandura A (1982) Self-efficacy mechanism in human agency. Am Psychol 37, 122-47. [CrossRef]

24) Shimomitsu $T$, Yokoyama $K$, Ono $Y$, Maruta $T$, Tanigawa $T$ (1998) Development of a novel brief job stress questionnaire. Report of the research grant for the prevention of workrelated diseases from Labour, 107-15.

25) Shimazu A, Schaufeli W, Kosugi S, Suzuki A, Nashiwa $\mathrm{H}$, Kato A, Sakamoto M, Irimajiri H, Amano S, Hirohata $\mathrm{K}$ (2008) Work engagement in Japan: validation of the Japanese version of the Utrecht work engagement scale. Appl Psychol 57, 510-23. [CrossRef]

26) Kessler RC, Barber C, Beck A, Berglund P, Cleary PD, McKenas D, Pronk N, Simon G, Stang P, Ustun TB, Wang P (2003) The world health organization health and work performance questionnaire (HPQ). J Occup Environ Med 45, 156-74. [Medline] [CrossRef]

27) Akizumi Tsutsumi ST, Mineyama S, Nishiuchi K,
Komatsu H, Kawakami N (2005) Effects of a supervisory education for positive mental health in the workplace: a quasi-experimental study. Journal of Occupational Health 47, 226-35.

28) Kageyama $T$, Kobayashi $T$, Kawashima M, Kanamaru $Y$ (2004) [Development of the Brief Scales for Coping Profile (BSCP) for workers: basic information about its reliability and validity]. Sangyo Eiseigaku Zasshi 46, 103-14. [Medline] [CrossRef]

29) Faul F, Erdfelder E, Lang AG, Buchner A (2007) G*Power 3: a flexible statistical power analysis program for the social, behavioral, and biomedical sciences. Behav Res Methods 39, 175-91. [Medline] [CrossRef]

30) Christie J, O'Halloran P, Stevenson M (2009) Planning a cluster randomized controlled trial: methodological issues. Nurs Res 58, 128-34. [Medline] [CrossRef]

31) Cohen J (1992) A power primer. Psychol Bull 112, 155-9. [Medline] [CrossRef]

32) van Rhenen W, Blonk RW, Schaufeli WB, van Dijk FJ (2007) Can sickness absence be reduced by stress reduction programs: on the effectiveness of two approaches. Int Arch Occup Environ Health 80, 505-15. [Medline] [CrossRef]

33) Wears RL (2002) Advanced statistics: statistical methods for analyzing cluster and cluster-randomized data. Acad Emerg Med 9, 330-41. [Medline] [CrossRef]

34) van Straten A, Cuijpers P, Smits N (2008) Effectiveness of a web-based self-help intervention for symptoms of depression, anxiety, and stress: randomized controlled trial. J Med Internet Res 10, e7. [Medline] [CrossRef]

35) Yamagishi M, Kobayashi T, Kobayashi T, Nagami M, Shimazu A, Kageyama T (2007) Effect of web-based assertion training for stress management of Japanese nurses. J Nurs Manag 15, 603-7. [Medline] [CrossRef]

36) Yamagishi M, Kobayashi T, Nakamura Y (2008) Effects of web-based career identity training for stress management among Japanese nurses: a randomized control trial. J Occup Health 50, 191-3. [Medline] [CrossRef]

37) Cook RF, Billings DW, Hersch RK, Back AS, Hendrickson A (2007) A field test of a web-based workplace health promotion program to improve dietary practices, reduce stress, and increase physical activity: randomized controlled trial. J Med Internet Res 9, e17. [Medline] [CrossRef]

38) Rowe MM (1999) Teaching health-care providers coping: results of a two-year study. J Behav Med 22, 511-27. [Medline] [CrossRef] 